\title{
UNESCO'S STRATEGY FOR REBUILDING HIGHER EDUCATION IN CRISIS AND EMERGENCY SITUATIONS
}

\author{
Olesya Gladushyna \\ Master's Degree Student in Research and Innovation \\ Higher Education Danube University Krems, Austria \\ gladushyna@gmail.com \\ $+380954532996$ \\ ORCID ID 0000-0001-7360-7223
}

\begin{abstract}
The paper analyzes the UNESCO's policy on protecting and development of the contemporary higher education (HE) which faces many challenges on the way towards its development, sustainability, and improvement. Moreover, the articles posits that the importance of determining crisis and emergency factors which impact the HE system in order to comprehend the role of UNESCO and its actions in supporting the HE system and universities in different regions of the world. Therefore, the concepts and characteristics of crisis and emergency risks are provided, the UNESCO's strategies in responding to the challenges of the contemporary HE in terms of its instability and potential external threats are defined as well as the relevance and effectiveness of mode of operations applied by UNESCO in regulating conflicts and other onerous situations pertinent to HE sector is reasoned.
\end{abstract}

Keywords: crisis management; emergency management; higher education; UNESCO.

\section{INTRODUCTION}

Numerous disagreements arise between states and change the educational landscape of regions; socio-economic problems make the HE fragile and put it at risk of arduous conflicts, natural disasters result in disruption of higher education institutions (HEIs) and lead to dramatic consequences. This creates difficulties and urges universities and other stakeholders to seek adequate responsive measures to meet external pressures. However, the recent cases demonstrated negligence and practical incapacity of states and universities to tackle the crisis situations arising from diverse sources. One of the typical criticism of crisis and transition response is that HE system and institutions react unprofessionally, slowly and lack the support of national and/or international community.

In this context, the United Nations Educational, Scientific and Cultural Organization (UNESCO) focuses on the drivers which might affect the progress of $\mathrm{HE}$ or threat its quality and stability as well as designs the ways to decrease the negative effects of crisis assisting $\mathrm{HE}$ and to find the most relevant actions for recovering. Therefore, UNESCO set up the Crisis and Transition initiative as a priority theme for its activities aiming at taking measures to neutralize unfavourable forces and maintain the advancement, accessibility and transparency of HE under crisis conditions. Contributing to the reconstruction in the field of education, science, culture, and communication in countries experiencing crisis or transition phase, UNESCO posits human and institutional 
dimensions as key elements for recovery and reconstruction processes as well as promotes continuous access, freedom of expression and information during and after crises. These actions are carried out in order to respond accurately to the menaces of the conflicts and threats, and thus, underpin the perspectives for effective and proper recovery stage to the permanent progress in the future.

It is worth pointing out that in our rapidly changing world the strategies and approaches to handle crisis and emergency circumstances have to be constantly reviewed and upgraded, if necessary. Hence, it is valuable and substantial to investigate the design, reasoning and implementation process of UNESCO's strategies and actions regarding regulation of crises affected HE systems especially in developing and transition countries which are distinguished by instability as well as lack of necessary human capital and infrastructure. Furthermore, UNESCO stands for a leading organization in terms of managing the educational, cultural and humanitarian issues, and its flagship projects are considered to be the best practices. Therefore, the analysis of the UNESCO's policy in crisis and transition response is an asset for the development of the practical recommendations for the crisis and emergency management field.

\section{ANALYSIS OF RELEVANT RESEARCHES AND PUBLICATIONS}

The area of rebuilding and strengthening the HE sector during or after the crunches encompasses such scientific realms as crisis, emergency, and risk management and applies the frameworks and techniques pertinent to these three types of management. The theoretical concepts of crisis, risk, and emergency management originated in early 1980 as a response to the large-scale industrial and environmental disasters occurred at that time and negatively influenced various organizations worldwide (Shrivastava et al., 1988; ASIS International, 2009). All three concepts are different from each other; nevertheless, there are common characteristics inherent in management of crisis, emergency and risk issues.

The researchers in the field of management studies Pearson and Clair (Pearson C., Clair J., 1998) were the first who proposed the comprehensive definition of crisis: "An organizational crisis is a low-probability, high-impact event that threatens the viability of the organization and is characterized by ambiguity of cause, effect, and means of resolution, as well as by a belief that decisions must be made swiftly" (Pearson C., Clair J., 1998: p. 60). Whereas Venette (Venette S. J., 2003) argues that crisis is a process which urges organizations to move through transformation and alters the previous system which appears to be no longer maintained. Another scholar Timothy Coombs (Coombs W. T., 2007) points out the perceptive aspect of the crisis situation inferring that crisis is an unpredictable event which menaces the stakeholders' interests and impacts an organization's performance with the result of negative outcomes.

On the other hand, emergency management or disaster management elaborates strategies and practical plans to reduce the vulnerability to threats and the ways to regulate the disasters (Drabek, 1991). In contrast with the crisis management, emergency management does not set a target to prevent or eliminate the menace, but to design appropriate and efficient procedures to decrease to the minimum the impact of disasters. Thus, the emergency management plans are composed and frequently reviewed by many US universities indicating the possible threats 
from manmade and natural disasters. Generally, these university plans cover such potential dangers as armed conflicts, terrorism, fire, earthquakes, hurricanes, sabotage and public strikes, information and communication failures, etc. Likewise Chinese universities located in hazardous regions have an obligatory emergency management plan and organize permanent special trainings for students and staff in order to familiarize them with survival strategies and the guidelines of behaviour in ongoing or post-disaster circumstances. The absence of the emergency plan and guidelines or incompetent actions during the disaster could lead universities to material damage, human mortality, loss of revenue and prestige, long-term instability.

The study on the correlation and cross-coupling between higher education sector and various conflicts or disasters has been relatively neglected, and as a consequence, it is still represents an under-research field. As noted by Tomlinson and Benefield in their significant work "Education and Conflict: Research and Research Possibilities" (2005), the methods of coping with conflicts at institutional, regional, and national levels remain inadequate and inefficient in conflict-affected countries. Nevertheless, recently the focus of policy-makers, academic community and mass media has been directed to the problems of crisis situations and their impact on the development and sustainability of higher education (Novelli, Lopes-Cardozo, 2008).

Tomlinson and Benefield (Tomlinson K., Benefield P., 2005) assert that education can facilitate the conflict resolution and bring benefits for the society and state. Despite of propaganda functions which universities can use for peaceful purposes, HEIs can maintain the sense of normality in people's lives by providing educational services and allowing student to attend the lectures or do the assignments. This becomes extremely important in the context of abnormal nature of conflicts or disasters when regular habitual mode of life is disorganized. Finally, if universities manage to reduce the social tension and assist to educate the society, it may advance the recovering and rebuilding of post-conflict HE system and environment.

Schneller's (2010) shares similar ideas and according to his point of view, crisis has also a potential to stimulate beneficial patterns for HEIs themselves, for instance, for financial autonomy of universities in terms of introducing the cost sharing model in the form of tuition and other fees, cost-recovery approaches which could foresee different types of student loans, and financial diversification promoting income-generation and fund-rising. These administrative novelties might have a positive impact on higher education institutions (HEIs) transforming them into less reliable on governmental budget and conform the institutional management to the environmental circumstances which require from them to adapt to new techniques and approaches in university governance.

The approach of elaborating different criteria of educational assessment depending on the circumstances and external pressure belongs to Alan Smith (Smith A., 2010). He remarks that in the framework of relatively peaceful context education system should act in a preventative way in order to avoid crisis situations. Meanwhile, in conflict times universities have to change their strategies and implement the protective approach by accomplishing its role for crisis regulation objectives. In this sense, HE may prove to be an influential tool to generate positive transformations in other state's sectors, to cope with conflict or crisis challenges as well as frame the future development plan of the country. 


\section{RESEARCH OBJECTIVE}

The topic of crisis, emergency and risk management in higher education has not been researched extensively and requires further development. Since UNESCO is a leading organization in education and peace building, its strategy related to the theme of crisis and transition response in higher education should be investigated as a valuable source of best practices in the field of mitigation and crisis resolution in HE sector. Moreover, the strategy covers the issues from basic and secondary education to higher education and adult learning, and there is a need to identify and extract the relevant information applicable to managing at-risk $\mathrm{HE}$ in concerned countries or regions. Therefore, research objective of the paper consists in carrying out an analysis of UNESCO's Strategy on crisis management in higher education revealing the key priority areas of strategic focus, its methodology of implementation as well as expected outcomes.

\section{RESULTS AND DISCUSSION}

In the Medium-Term Strategy 2002-2007 UNESCO positions itself as an international leader in education, science, culture and communication by accomplishing a role of an idea generator, standard-setter, a capacity builder and a catalyst for boosting and developing international cooperation. Recurrently UNESCO justifies this role by initiating various projects to solve the emerging issues of tertiary education in conflict and disaster zones. Behind UNESCO's projects in the field of crisis and transition response in HE there are specific strategies which determine the nature and characteristics of UNESCO's projects and shape the education policy not only at UN level, but also worldwide.

Throughout the years UNESCO has been promoting and assisting conflict regulation and reconstruction of $\mathrm{HE}$, and thus, its strategy turns out to be a result of the certain contributions to provide HE service to youth and adults, to support universities and reinforce their potential to continue functioning during or after critical events. Furthermore, UNESCO has to connect its strategies with the goals of other United Nations (UN) agencies bringing value added actions and fulfilling the UN's essential mission which is capacity and peace building contribution to different countries.

Strategic objectives for HE which UNESCO approved and actively puts in practice can be formulated as follows:

- advancing education for all paying attention to accessibility and gender issues;

- $\quad$ improving the quality of educational services and university organization through diversification of contents, methods, and approaches;

- $\quad$ transforming HEIs into a powerful distributor of shared values for society;

- $\quad$ stimulating experimentation and innovation to modernize, harmonize and make HE more efficient;

- disseminating information on the vital challenges for contemporary HE, sharing best practices as well as initiating sustainable dialogue on HE problems and perspectives among nations.

Nevertheless, the promotion of education as a universal and fundamental right for all encounters specific obstacles because under crisis situations governments, 
donors and society tend to underestimate the urgency of rebuilding the access to HE. There is also a threat to neglect the quality of education in situations of emergency or crisis, whereas universities are capable to meet psycho-social needs of citizens affected by critical circumstances. Acknowledging all these barriers facing HE in specific context, in its strategic plan UNESCO expresses the need to create a multidisciplinary network of practitioners and researchers in HE in order to prompt policy research and information sharing on HE for crisis-affected society. In the long-term perspective, such a network should study the possible scenarios for HE development in crisis through a variety of macro and micro level programs, which, in their turn, will be designed to bring universal concepts of peace, tolerance and equity.

Although emergency component is a considerable part of higher education management, UNESCO believes that emergency actions should be designed by specialists in emergency situations and it should be out of the scope of educators' duties (UNESCO, 2010). Nevertheless, the strategy foresees the active involvement of education planners, national decision makers, HE managers into trainings provided by emergency specialists on diverse emergency techniques which might be effectively used in HE sector.

In its turn, institutional development and effective management constitute the core factor of successful mitigation and rebuilding and require valid support on behalf of regional and national authorities. The assistance could be evident in the reinforcement of national policy aiming at developing management leadership along with strengthening the opportunities of institutional human capital. It is particularly significant to highlight the critical lack of basic resources within HEIs under crisis, and in addition, university staff might not be experienced in dealing with managerial or teaching issues in the situation of conflicts or disasters. In this regards, in its strategy on education in situations of emergency, crisis and reconstruction, UNESCO points out that human resources engaged in HE system need to develop and improve their expertise in education planning and management. It can be achieved through a set of actions namely modernization of curricula to prepare future educators to handle professionally crisis situations and special trainings which can be arranged under the coordination of international parties.

Since rehabilitation of HEIs plays a considerable role in the strategy, UNESCO allocates support to diversify the university methods of delivering and managing education for youth and adults. It might be accompanied with the necessity to renew a university vision and mission, acquirement and implementation of innovative forms in terms of providing educational programs for students or trainings for staff, for example, through distance learning means which allow reaching target audience. Universities in crisis situations may use distance learning as a method to introduce the crisis management approaches which are applied at universities, to familiarize students and staff with skills and competences which are necessary to cope expertly with conflicts and other challenges as well as to promote shared valued and understanding on crisis situations.

The desired activities bring the need to update structure for the whole $\mathrm{HE}$ system, to renew approaches to evaluate and assess the quality of education and urge for adoption of basic principles, norms and standards for HE under crisis to ensure the normative function. Naturally, many agencies that are involved in regulation of crisis and emergency education have elaborated independent guidelines, norms and standards for $\mathrm{HE}$ functioning in terms of critical 
circumstances. However, it might be concluded that this fact is not beneficial for HE systems since it might lead to disorientation when various standards are applicable in adjacent regions. International conferences and symposiums organized by UNESCO should seek the comprise between the need to develop special criteria for assessment and the obligation to conform them with the existing as well as determine the conditions when the criteria for HE under crisis should start to be in use.

It is important to underline the preventive function of universities which has to be identified and clearly stated in the guidelines and instructions on managing $\mathrm{HE}$ affected by conflict or disaster events. For instance, the armed conflict in Eastern Ukraine showed that universities neither assessed the situation, nor took any measures to mitigate the crisis. The emerged conflict in Ukraine was grounded in the language, religious, ethnic and political divergence, and the HEIs should have used their preventive function to avoid the aggravation of the conflicts through support of cultural and linguistic diversity at least at institutional level. Therefore, the UNESCO's strategy proves to be relevant since it envisages the launch initiatives regarding promoting the idea of cementing the HE management and the preventive actions as part of university agenda.

Ensuring the right to education in situations of emergency and crisis is one of the priorities in UNESCO's strategy. Linking this issue to the example of Eastern Ukrainian universities and the military conflict which had place in 2014, it is evident that the government did not assure the right of pursuing HE studies for students. Thus, internally displaced students from conflict-affected regions might have had an opportunity to continue their studies at universities in peaceful areas of Ukraine and they could have been accepted as non-degree students. Nevertheless, in this case students had to present certificates and transcripts of records from their home HEIs in order to be enrolled as visiting students in other regions of Ukraine. Obviously, it created certain difficulties because academic and administrative staff was not available at universities in the conflict zone and could not present such letter of confirmation or certificates. Moreover, the status of non-degree students was nominal because this kind of students were not graded, and hence, their studies at host universities could not be recognized as part of their academic program and could not be further documented in their transcript of records (Dmitrenko, 2015). This is one of the cases when the right to HE in emergency and crisis situations has to be reconsidered and well deliberate. And UNESCO will advocate including the provision of $\mathrm{HE}$ in critical circumstances for the society as the priority area of the humanitarian response and as a basic human right for all.

Concerning refugees and asylum-seekers, UNESCO states the need to facilitate the admission requirement and negotiate with the governments which provide asylum regarding the tuition fees for refugees that represent a vulnerable group of society. The strategic aim of UNESCO is to give an opportunity for refugee students to be enrolled in foreign countries for free or paying the same amount of tuition fees as local students are charged for their studies since certain countries and HEIs tend to equal the status of refugee students to that of regular foreign students which implies much higher tuition fees. UNESCO aims at creating a database or observatory to examine the implementation of the right and access to $\mathrm{HE}$ in situations of both crisis and post-crisis reconstruction. In the strategy on education in situations of emergency and crisis the problem of discontinuation 
of HE studies is emphasized, and it becomes extremely important to maintain the open ladder of educational opportunities for youth and adults because they will act as determinants of the future country's development.

Another point of focus is the education for students with disabilities who require special support and assistance in particular in crisis or disaster circumstances. International community, governments and HEIs themselves have to ensure the integration of disabled students into HE academic programs to the maximum possible extent and the appropriate methodology to provide students with the required learning outcomes. UNESCO intends to survey programs and materials designed to satisfy the expectations and demands of students with special needs. In the cooperation with partners and through its offices, UNESCO will raise awareness on the above-mentioned issues as well as develop action plan for local and national initiatives.

Decentralization represents one of the management tools which UNESCO applies to promote education in emergency, crisis and post-conflict situations through its field offices. The concept of decentralization foresees the contextualization of UNESCO's strategy in particular regions and elaboration of guidelines and handbooks which might be used for regulation and/or mitigating critical factors and events which threat the efficiency of HE system.

It might be argued that in most cases educational planning has been taken conventionally even under the dramatic situations of emergency or conflicts without prompt response to the rising challenges and elaboration of appropriate measures to stabilize post-conflicts HE environment. In this regard, governments and HEIs have to prepare beforehand the instructions on how to act at institutional, regional or national levels in embarrassing situations of crisis. Nevertheless, UNESCO recognizes the need of support and professional guidance for those states and local authorities that are obliged to deal with conflicts and disasters. To help them and assist in achieving favorable outcomes UNESCO implements participation mode of operation which means its active involvement in systematic consultancy and guidance to concerned countries. UNESCO will focus on the reconstruction and consolidating potential of HE system and HEIs as well as will activate the search for best solutions and decision through cooperation with both specialized HE research centres considering community-based approach.

Damaged infrastructure, lack of basic facilities and weak level of safety result in restricted and limited application of information and communication technologies for educational purposes under crisis circumstances. Therefore, UNESCO will ensure that HEIs are provided with assistance in terms of provision of computerliterate staff and trainers who are capable to manage the new mission and actions of universities through online resources. At the same time, UNESCO aims to design a website which could serve as a tool for gathering the best practices on education in emergency and crisis situations as well as data on current projects and initiatives in the field. This will be accompanied by ongoing technical discussions on the standardization of reports and database on emergency education programs.

Advocacy forms an operational tool for UNESCO to raise awareness among international community on the challenges in at-risk HE. This includes the strengthening of linkages between the activities undertaken by various supranational, national, regional organizations and those of UNESCO's targeting at combining joint effort for HE reconstruction. For this reason, UNESCO will meet potential donors to attract enhanced funding for core activities in the 
field of $\mathrm{HE}$ systems under crisis and reinforce the realization of assistance and reconstruction $\mathrm{HE}$ programs in a long-term perspective.

Capacity building is in the spotlight of UNESCO and is identified as a mode of operation to build strong leadership at universities and empower academic and administrative staff to acquire skills and competences needed to handle unusual and tense circumstances in which their institutions might have to operate or are already involved. Hence, at grass-roots level special programs have to be designed and implemented in an attempt to familiarize and train educators to deal with crisis and emergency cases.

A top priority is given to assessment and evaluation aspects of UNESCO's work in the field of crisis and emergency management in HE. Since there has been inadequate evaluation of at-risk HE, there is an urgent need to conduct state of the art investigation on the preventative and reconstruction procedures and techniques applicable to HE system and universities in unstable regions. The long-term and regular studies on the transition and post-conflict process of HE under crisis would lead to the deep understanding of different risks that menace universities and will foster the elaboration of powerful and effective approaches to future diagnose of potential threats, implementation of reconstruction programs and sustainability plans. There is strong evidence that nowadays there is a lack of solid ground for national and institutional policy concerning the above-mentioned matters. The primary aim of updated state of the art studies is to accelerate progress and improvement of basic tools for emergency, crisis and transition response. At this point UNESCO seeks the ways to integrate scientific and research community to contribute to the examination of relevant questions and design appropriate and contextualized measures to be taken depending on the nature of crisis or conflict as well as the on the peculiarities of cultural, infrastructural, leadership and other features of universities.

\section{CONCLUSIONS}

The topic of crisis and emergency management in HE has not been researched deeply and requires further investigation in order to identify and contextualize the variety of risks which threaten the modern HE system as well as to determine the key strategies for improving the current situation of HEIs in conflict or postconflict environment. Crisis is associated with negative impact on educational structure and functioning; however, using appropriate measures to mitigate the emergency or crisis events could urge universities to streamline their mission, services and long-term perspectives.

UNESCO as a world leading organization in education focuses also on specific issues of delivering and managing $\mathrm{HE}$ in crisis and emergency situations. The analysis of UNESCO's strategy demonstrated its relevance to the challenges arising from conflicts or disaster and which undermine the quality, effectiveness and accessibility of HE for youth and adults. Therefore, the strategy of UNESCO focuses on the crucial problems which are pertinent to many at-risk regions and HEIs before, during and after crisis events. Based on its strategy, UNESCO defined a concrete implementation plan for achieving the desired strategic goals, pinpointing practical aspects of the prospective actions. Thus, the attention is given to strengthening restoration and reconstruction functions, updating the HE delivery methods, provision of special trainings for university representatives, policy makers and education planners to raise their awareness on the best practices 
of handling with crisis and disasters along with maintaining the functioning of HEIs to the maximum possible extent. Normative function should be improved by including standards and norms on regulating and evaluating HEIs under crisis elaborated by UNESCO into the national agenda especially of unstable countries. It requires a vital cooperation of UNESCO with other UN agencies as well as with governmental and non-governmental organizations. The strategy also foresees the active involvement of scientific and research centres into contextualization process of diverse threats and design of particular guidelines and handbooks for a specific fragile region. Along with these initiatives it is envisaged to create a database to disseminate widely the best experiences in HE under crisis.

Hence, the UNESCO's strategy on HE in emergency, crisis and reconstruction proves to be significant and consistent to the UN's mission of promoting universal shared values and supporting tertiary education for the development and wellbeing of countries. Due to the changing nature of contemporary HE, demands from society and emerging situations, UNESCO has to review and access its strategy on a regular basis to ensure the appropriateness of it and capacity to mitigate the challenges in HE and empower universities to accomplish successfully their mission even in such complex situation as conflict or post-conflict environment.

\section{IMPLICATION FOR FUTURE RESEARCH}

The perspective for the further investigations in this field is the study, modelling and forecasting the behaviour of the HE system and HEIs and its necessary transformations under crisis, emergency situations and in post-conflict phase. Additionally, the implication can be found in the contextualization of the UNESCO's strategy at national, regional and/or institutional levels. The development of appropriate scientifically based proposals and action programs for a separate HEI and/or the HE sector in general might apply the elaborated principles, standards and norms of UNESCO's strategy on education in situations of emergency, crisis and reconstruction.

\section{REFERENCES}

1. ASIS International. Organizational Resilience: Security, Preparedness, and Continuity Management Systems-Requirements with Guidance for Use. ASIS SPC. American National Standard. (2009), 1.

2. Coombs, W. (2007). Ongoing Crisis Communication: Planning, Managing and Responding. Thousand Oaks, CA: Sage.

3. Dmitrenko, Y. (2015). Adaptation of internally displaced people into university environment by the means of student self-governance. Poltava: Poltava National Pedagogical University named after V. T. Korolenko.

4. Drabek, T. (1991). Emergency Management: Principles and Practice for Local Government. Washington D. C.: International City Management Association.

5. Global Education Monitoring Report (2016). Retrieved from http:// en.unesco.org/gem-report/about

6. Global Education Cluster. Integrating Conflict and Disaster Risk Reduction into Education Sector Planning. (2011). Retrieved from http://toolkit.ineesite.org/ resources/ineecms/uploads/1053/IIEP_Guidance_notes_EiE_EN.pdf 
7. Horvat, P. (2010). Conflict and Education - Data Analysis on the Public's Views on Education in Conflict-Affected Countries. Education for All Global Monitoring Report 2011. The Hidden Crisis: Armed Conflict and Education, Paris: UNESCO.

8. Novelli, M., Mieke, L. (2008). Conflict, Education and the Global South: New Critical Directions. International Journal of Educational Development, 28(4): 473-488.

9. Pearson, C., Clair, J. (1998). Reframing Crisis Management. Academy of Management Review, 23(1), 59-76.

10. Seeger, M., Sellnow, T., Ulmer, R. (1998). Communication, Organization and Crisis. Communication Yearbook, 21, 231-275.

11. Shrivastava, P. (1988). Understanding Industrial Crises. Journal of Management Studies, 25(4), 285-304.

12. Smith, A. (2010). The Influence of Education on Conflict and Peace Building. Education for All Global Monitoring Report 2011. The Hidden Crisis: Armed Conflict and Education. Paris: UNESCO.

13. Tomlinson, K., Benefield, P. (2005). Education and Conflict: Research and Research Possibilities. Berkshire: National Foundation for Educational Research.

14. UNESCO. Education in Situations of Emergency, Crisis and Reconstruction. UNESCO Strategy. (2010). Paris: UNESCO.

15. Venette, S. (2003). Risk Communication in a High Reliability Organization: APHIS PPQ's Inclusion of Risk in Decision Making. Ann Arbor, MI: UMI Rroquest Information and Learning. 